This item was submitted to Loughborough's Research Repository by the author.

Items in Figshare are protected by copyright, with all rights reserved, unless otherwise indicated.

\title{
Guest editorial: special issue on plenary and invited papers from ICOPS'2012
}

PLEASE CITE THE PUBLISHED VERSION

http://dx.doi.org/10.1109/TPS.2013.2253357

PUBLISHER

(C) IEEE

VERSION

AM (Accepted Manuscript)

\section{PUBLISHER STATEMENT}

This work is made available according to the conditions of the Creative Commons Attribution-NonCommercialNoDerivatives 4.0 International (CC BY-NC-ND 4.0) licence. Full details of this licence are available at: https://creativecommons.org/licenses/by-nc-nd/4.0/

\section{LICENCE}

CC BY-NC-ND 4.0

\section{REPOSITORY RECORD}

Iza, Felipe, Carl Ekdahl, and Michael G. Kong. 2019. "Guest Editorial: Special Issue on Plenary and Invited Papers from ICOPS'2012”. figshare. https://hdl.handle.net/2134/22151. 


\section{Special Issue on Plenary and Invited Papers From ICOPS 2012}

The 39th International Conference on Plasma Science (ICOPS) was held in Edinburgh, Scotland in July 2012. This was the third time that the conference was organized outside North America, the previous ones being in Karlsruhe (Germany) in 2008 and Jeju (S. Korea) in 2003. The technical programme combined seven technical areas of plasma science and technol ogy covering a wide range of topics. The conference featured a wide range of advances in innovative plasma and beam science and applications, and served as a venue for an international community to meet and discuss their ideas and research results. More than 800 abstracts were received in 35 different topical areas, with more than half the papers originated outside the United State. The conference was attended by over 600 delegates and counted with the participation of over 200 registered students.

The technical programme included 7 plenary talks by world leading scientist including Prof. G. Mesyats, recipient of the 2012 IEEE Marie Sklodowska-Curie Award for "founding the field of nanosecond pulsed power and seminal contributions to the physics of vacuum breakdown at high power levels" and Prof. Andrew Ng, recipient of the Plasma Science and Applications (PSAC) Award for his "outstanding research and visionary leadership in plasma research, particularly in the area of Warm Dense Matter, as well as his many contributions to the plasma science and applications community" .

This Special Issue of the IEEE TRANSACTIONS ON PLASMA SCIENCE contains eight refereed papers representing a small collection of some of the most exciting presentations from ICOPS 2012. A comprehensive review of the physical processes in cathode spots of vacuum arcs is presented in the article by Gennady Mesyats. Mesyats develops a model of explosive emission, and applies it to explain an extensive collection of experimental data This paper is destined to become an important reference for workers in the field of vacuum arcs. The field of electromagnetic radiation production by electron beams is represented by articles from N. S. Ginzburg et al. and M. Franzl et al. Ginzburg et al. discuss a wide range of different mechanisms for creation of superradiant emission by short electron bunches. In their article, Franzl et al. present simulations and experimental results of microwave production by a novel magnetron device. Gary Eden et al. explore plasma science and technology in the limit of the small and discuss microcavity plasmas and their emerging applications in an exciting overview of recent work. In the basic phenomena area, Luis Conde reports on emissive Langmuir probes in the strong emission regime for the determination of the plasma properties and the influence of thermionic emission in the interpretation of measurements. In his paper, Raj deep Rawat discusses the exciting prospects of high-energydensity pinch plasma as a unique non-conventional tool for plasma nanotechnology. Kostya Ostrikov presents an interesting article on sustainable nanoscience for a sustainable future and on the technol ogical side, Paul K. Chu provides an insightful review on the control of surface degradation on biodegradable magnesium alloys.

As guest editors, we would like to thank the authors for the excellent papers in this special issue. We hope this special issue will encourage the publication of similarly high-quality papers from future invited and plenary tal ks given at future ICOPS meetings. We al so thank the many referees for their time spent in providing careful and thoughtful comments on the manuscripts. Special thanks go to the Editor-in-Chief, Dr. Steven J. Gitomer, for his support and help with details pertaining to the preparation of this special issue. The papers in this special issue were processed entirely using the IEEE Manuscript Central system, a web-based system for the submission and review of manuscripts, which greatly simplified the management of the process.

FELIPE IZA, Guest Editor

School of Electronics, Electrical and Systems Engineering

Loughborough University

Leicestershire LE11-3TU, UK

CARL EKDAHL, Guest Editor

DARHT Accelerator Group

Los Alamos National Laboratory

Los Alamos, NM 87545 USA

MiCHAEL G. Kong, Guest Editor

Department of Electrical and Computer Engineering

Old Dominion University

Norfolk, VA 23529 USA 


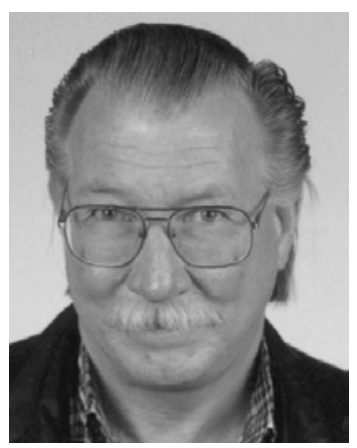

Carl Ekdahl received the B.A. degree in physics from San Diego State College, San Diego, CA, and the M.S. and Ph.D. degrees in physics from the University of California at San Diego, La Jolla. He has engaged in experimental physics at Scripps Institute of Oceanography, San Diego, CA, Cornell University, Ithaca, NY, Mission Research Corporation, Albuquerque, NM, Sandia National Laboratories, Albuquerque, NM, and Los Alamos National Laboratory, Los Alamos, NM. His research interests include accelerators and intense relativistic electron beams, high energy density plasmas, and high energy density hydrodynamics. He presently leads a team responsible for diagnostics and beam physics experiments on the DARHT-II accelerator at Los Alamos National Laboratory.

Dr. Ekdahl has previously served on various IEEE award and conference organizing committees, and he is a Member of the American Physical Society Division of Beams and Plasma Physics.

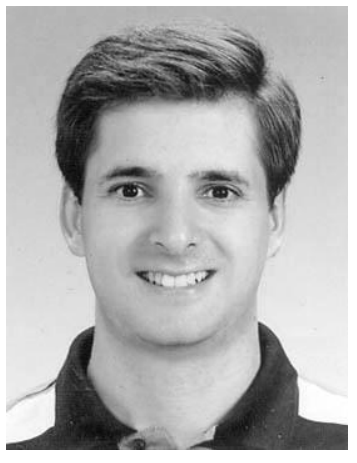

Felipe Iza (M’02-SM'11) received the B.S. degree in engineering from the University of Navarra, San Sebastian (Spain), in 1997, and the M.S. and Ph.D. degrees from the Northeastern University, Boston MA (USA), in 2001 and 2004, respectively. From 1997 to 1999, he was with CEIT, San Sebastian (Spain). From 2004 to 2006, he was a Postdoctoral Fellow with POSTECH (Korea), where he became a Research Professor in 2006. Since 2007, he has been a Lecturer with the School of Electronic, Electrical and Systems Engineering, Loughborough University, U.K. His research interest is focused on experimental and computational lowtemperature plasma physics and engineering, with special attention to microplasmas and atmospheric discharges for biomedical and environmental applications.

Dr. Iza is a Fulbright alumnus, a senior member of the Institute of Electrical and Electronics Engineers (IEEE), and member of the Institute of Physics (IoP). He served as treasurer and local organising committee chair of ICOPS 2012.

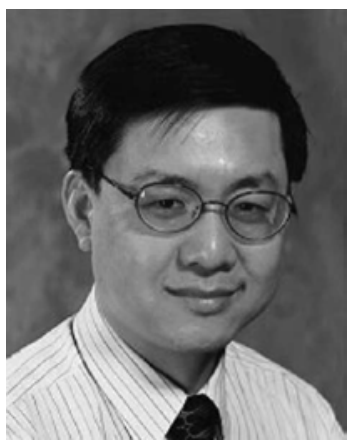

Michael G. Kong (M’94-SM’98) received the B.Sc. and M.Sc. degrees in electronics engineering from Zhejiang University, Hangzhou, China, in 1984 and 1987, respectively, and the Ph.D. degree in electrical engineering from Liverpool University, Liverpool, U.K., in 1992. After research and faculty positions at Liverpool University and Nottingham University, Nottingham, U.K., he joined Loughborough University, Loughborough, U.K., in 1999, where he held a Chair in bioelectrical engineering and became the Head of the Energy Research Division. Since 2012 he is with the Old Dominion University where he is a professor of Electrical and Computer Engineering and Batten Endowed Chair in Bioelectrics. His current research interests include atmospheric pressure glow discharges, ultrashort electric pulses, and their biomedical applications. In these areas and others, he has published some 150 papers in scientific journals and peer-reviewed conference proceedings. 